the disease. We have not yet assessed this form of treatment more widely in the disease.

\section{References}

${ }^{1}$ Inman RD. Immunologic sex differences and the female preponderance in systemic lupus erythematosus. Arth Rheum 1978;21:849-59.

2 Talal N, ed. Proceedings of the Kroc Foundation conference on sex factors, steroid hormones and the host response. Arth Rheum 1979;22: 1153-1320.
${ }^{3}$ Lahita RG, Bradlow HL, Kunkel HG, Fishman J. Alterations of oestrogen metabolism in systemic lupus erythematosus. Arth Rheum 1979;22: 1195-8.

${ }^{4}$ Panser K, Gell J, Gelfand J, Turksoy N, Agnello V. Pilot studies in the use of danazol in the treatment of patients with systemic lupus erythematosus. Rev Rhum Mal Osteoartic 1981 ;48,suppl:483.

${ }^{5}$ Hazelton RA, McCruden A, Stimson WH, Sturrock RD. The effects of 19-nortestosterone treatment on clinical and laboratory parameters in patients with systemic lupus erythematosus. Ann Rheum Dis $1981 ; 40$ : 626.

(Accepted 23 December 1981)

\title{
Gastric carcinoma and thrombotic thrombocytopenic purpura: association with plasma immune complex concentrations
}

\author{
STEVEN E ZIMMERMAN, FREDERICK P SMITH, TERENCE M PHILLIPS, ROBERT J COFFEY, \\ PHILIP S SCHEIN
}

\begin{abstract}
A patient with metastatic adenocarcinoma of the stomach developed microangiopathic haemolytic anaemia, thrombocytopenia, renal insufficiency, and fluctuating neurological abnormalities in association with appreciably raised plasma concentrations of immune complexes. This syndrome, similar to thrombotic thrombocytopenic purpura, occurred while the tumour was in sustained objective remission after successful treatment with fluorouracil, doxorubicin, and mitomycin. Reversal of the syndrome was achieved with plasmapheresis, azathioprine, corticosteroids, and antiplatelet treatment; this response was paralleled by a reduction in immune complex concentration, suggesting an immune aetiology for the syndrome. Antibodies eluted from the immune complexes reacted with $50 \%$ of cells from the gastric cancer but less than $10 \%$ of cells from normal gastric mucosa. There was no reactivity with either carcinoembryonic antigen or mitomycin. A 17S immune complex reacted with a glycoprotein from the patient's autologous platelets and produced platelet aggregation.

It is postulated that reducing the tumour and the pre-existing state of antigen excess by chemotherapy allowed soluble antigen-antibody complexes to form and the syndrome to develop.
\end{abstract}

\section{Introduction}

Microangiopathic haemolytic anaemia has been described in association with disseminated malignancies, most commonly adenocarcinoma of the breast or stomach. ${ }^{1-3}$ Recently a syndrome

Division of Medical Oncology, Vincent $T$ Lombardi Cancer Research Centre, and Department of Pathology, Georgetown University Medical Centre, Washington, DC 20007, USA

STEVEN E ZIMMERMAN, MD, clinical fellow, medical oncology FREDERICK P SMITH, MD, assistant professor, medical oncology TERENCE M PHILLIPS, PHD, assistant professor, pathology ROBERT J COFFEY, MD, clinical fellow, medical oncology PHILIP S SCHEIN, MD, MRCP, chief of division of medical oncology resembling thrombotic thrombocytopenic purpura, manifested by microangiopathic haemolytic anaemia, thrombocytopenia, and renal insufficiency, has been reported in patients with adenocarcinomas, particularly of the stomach, ${ }^{45}$ and in two patients with epidermoid carcinoma. ${ }^{6}$ Microangiopathic haemolytic anaemia is usually a late and fatal complication of advanced metastatic carcinoma. ${ }^{2}$ In contrast, most patients with the syndrome similar to thrombotic thrombocytopenic purpura have had only microscopic or no evidence of active tumour after effective treatment with chemotherapy. ${ }^{4-6}$

The association of thrombotic thrombocytopenic purpura with disorders of the immune system such as lupus erythematosus ${ }^{7}{ }^{8}$ in addition to the findings of raised plateletassociated IgG concentrations ${ }^{910}$ and the presence of immunoglobulin and complement in the characteristic vascular lesions ${ }^{11}$ have supported an immune aetiology. Although the role of circulating immune complexes in producing vascular injury, with the resultant clinical syndrome, has been widely speculated, ${ }^{12-15}$ only recently has the presence of such complexes in a patient with thrombotic thrombocytopenic purpura been documented. ${ }^{16}$ We report on a patient with metastatic adenocarcinoma of the stomach who developed microangiopathic haemolytic anaemia, thrombocytopenia, renal insufficiency, and fluctuating neurological abnormalities in association with considerably raised plasma immune complex concentrations.

\section{Case report}

In July 1979 a 48-year-old woman was found to have unresectable gastric carcinoma. Histology showed a mucin-producing adenocarcinoma of the linitis plastica type affecting the entire thickness of the gastric wall, and lymph node and mesenteric metastases were noted. A gastrojejunostomy was performed with no attempt at tumour resection. Before chemotherapy with the FAM regimen (fluorouracil, doxorubicin (Adriamycin), and mitomycin) ${ }^{17}$ was started in August abdominal sonography was performed, which showed a mass in the left upper quadrant and ascites. Until March 1980 she received four full cycles of treatment with appropriate dose modification during the fourth cycle for mild thrombocytopenia (platelet count of $\left.128 \times 10^{9} / 1\right)$. During this time she showed symptomatic improvement, with an increased appetite and weight gain of $0.7 \mathrm{~kg}$; repeat abdominal sonography showed complete disappearance of the mass and no evidence of ascites.

In April she was readmitted to hospital for evaluation of progressive anaemia, thrombocytopenia, episodic fever, intermittent dysphasia, 
and weakness of the left arm. Evaluation before admission had included computed tomography of the brain, which yielded a normal scan, and abdominal sonography and chest $x$-ray examination, which failed to show evidence of recurrent tumour. On admission she was alert, oriented, and in no apparent distress. There was no palpable lymphadenopathy, petechiae or ecchymoses, abdominal masses, or detectable ascites. Neurological examination was remarkable only for episodic stuttering of speech.

Packed cell volume was 0.21 , haemoglobin concentration $9.0 \mathrm{~g} / \mathrm{dl}$, reticulocyte count $0.9 \%$, white cell count $9.1 \times 10^{9} / 1$, and platelet count $70 \times 10^{9} / 1$. A peripheral blood smear showed numerous burr cells, schistocytes, and helmet cells. A bone-marrow aspirate and biopsy specimen showed mild hypocellularity with an adequate number of megakaryocytes. Serum haptoglobin was not detectable. Blood urea nitrogen concentration was $11.4 \mathrm{mmol} / \mathrm{l}(32 \mathrm{mg} / 100 \mathrm{ml})$, creatinine concentration $115 \mu \mathrm{mol} / 1(1.3 \mathrm{mg} / 100 \mathrm{ml})$, and creatinine clearance $42 \mathrm{ml} / \mathrm{min}$. Activities of lactic dehydrogenase, serum aspartate transaminase, and serum alanine transferase and bilirubin concentrations were within normal limits. Urine analysis showed 10-12 red blood cells/high power field, eight to 10 white blood cells/ high power field, $4+$ proteinuria, and numerous granular and hyaline casts. The prothrombin time was $11.5 \mathrm{~s}$ (control $11.4 \mathrm{~s}$ ) and partial thromboplastin time $33.2 \mathrm{~s}$ (control $30.5 \mathrm{~s}$ ). The thrombin time was slightly prolonged at $27.3 \mathrm{~s}$ (control $20.6 \mathrm{~s}$ ). Fibrinogen concentration was $3.85 \mathrm{~g} / \mathrm{l}(385 \mathrm{mg} / 100 \mathrm{ml})$. Fibrin degradation products determined by latex agglutination were $20 \mathrm{mg} / 1$ (normal $10 \mathrm{mg} / \mathrm{l}$ ). A direct Coombs test and tests for rheumatoid factor and antinuclear antibody yielded negative results, and total haemolytic complement was normal. $X$-ray examination of the upper gastrointestinal tract, liver and spleen scans, and abdominal sonography showed no evidence of progressive tumour with chest.

Immune-complex analysis on the initial plasma sample showed $43 \%$ binding inhibition by the $\mathrm{Clq}$ assay $^{18}$ (normal range 1-6\% binding inhibition) and an immune complex concentration of $324 \mathrm{mg} / \mathrm{l}$ by the Raji cell assay ${ }^{19}$ (normal range $10-65 \mathrm{mg} / \mathrm{l}$ ). Polyethylene glycol sedimentation of the plasma followed by double-crossed immunoelectrophoresis ${ }^{20}$ showed two medium bands $(17 \mathrm{~S}, 22 \mathrm{~S})$ and one heavy band (44S). The $17 \mathrm{~S}$ band was found to contain an IgG antibody, which was examined by immunodiffusion against its antigen as well as against prepared dissolved autologous and allogeneic platelet membranes. A line of identity between the antigen and a glycoprotein from the patient's autologous platelets was found. This $17 \mathrm{~S}$ immune complex also produced greater than $80 \%$ platelet aggregation in five minutes. The $22 \mathrm{~S}$ band contained $\mathrm{IgG}$ and an unidentified protein; the $44 \mathrm{~S}$ band contained only IgG reacting with
IgG, with no identifiable antigen. Neither the $22 \mathrm{~S}$ nor the $44 \mathrm{~S}$ immune complex produced platelet aggregation.

The eluted antibodies from the immune complexes were also tested for reactivity against mitomycin by double diffusion in agarose gel. The antibodies were concentrated to $1 \mathrm{~g} / 1$ by negative-pressure dialysis and reacted against a $1 \mathrm{~g} / 1$ solution of the drug. Diffusion in agarose plate wells was allowed to take place over 24 hours and the plates read in diffuse light after being soaked in $8 \%$ saline to intensify the reaction. No reactivity with mitomycin was seen with any antibody eluted from the complexes. In addition, all of the complexed antibodies were tested for reactivity to carcinoembryonic antigen by an enzyme-linked immunoassay and failed to show reactivity.

Reactivity of the separated antibodies with the tumour was determined by immunofluorescence. Sections of the tumour were cut from paraffin-embedded material, dewaxed in cold xylene, and equilibrated by passage through cold alcohols. The sections were stained by the indirect immunofluorescence method of Phillips and Lewis $^{21}$ using $1 / 4$ and $1 / 8$ dilutions of the patient's antibody dissociated from the medium band complexes, and goat antihuman IgG conjugated to fluorescein isothiocyanate. The tumour specimen from the original operation showed staining of greater than $50 \%$ of the cells, whereas normal gastric tissue from necropsy specimens had less than $10 \%$ staining. Normal gastric tissue obtained during the second abdominal exploration, which contained no microscopic tumour, failed to cross-react with the antibody.

A tumour-associated syndrome similar to thrombotic thrombocytopenic purpura was diagnosed, and treatment with corticosteroids (prednisone $80 \mathrm{mg}$ daily) and dipyridamole (400 $\mathrm{mg}$ daily) was started. After the demonstration of circulating immune complexes plasmapheresis was begun using an Aminco cell separator and was performed on five occasions, with exchange of four to five litres of plasma on each occasion. Within 25 days of the start of treatment the immune complex concentrations gradually declined from 324 to $32 \mathrm{mg} / \mathrm{l}$ as measured by the Raji method, and from $43 \%$ to $5 \%$ by the Clq-binding technique (figure). Azathioprine ( $3 \mathrm{mg} / \mathrm{kg} /$ day) was added after the third plasmapheresis, and the platelet count progressively rose from $40 \times 10^{9} / 1$ to $110 \times 10^{9} / 1$ by day 32 , which corresponded to the progressive decrease in immune complex concentrations. Prednisone was gradually stopped and chemotherapy with the FAM regimen resumed. Azathioprine was subsequently stopped because of contributing haematological toxicity.

She was maintained on the FAM regimen for six additional months, with appropriate dose modifications for haematological toxicity. Plasma immune complex concentrations remained in the normal range. The peripheral blood smear returned to normal;

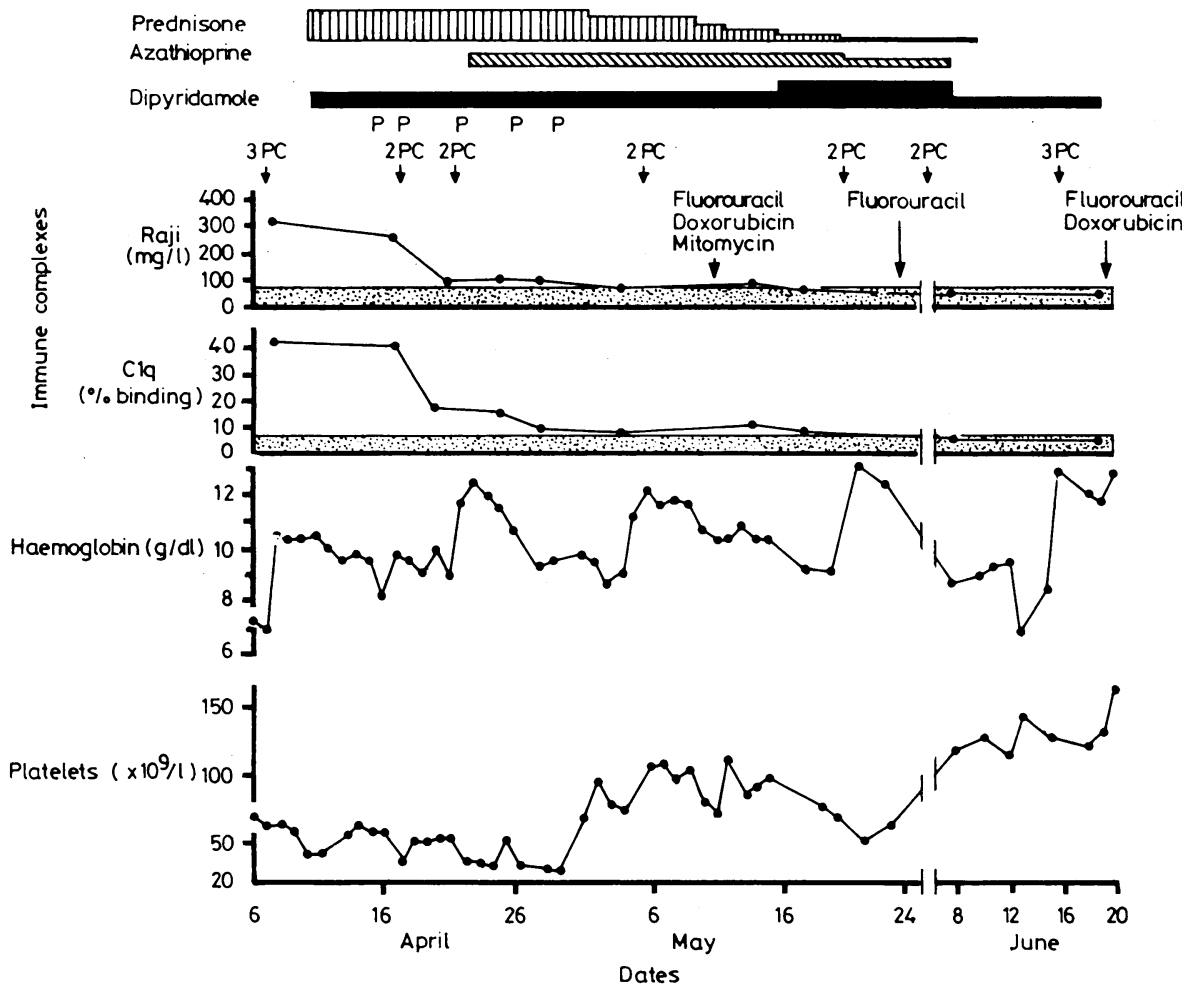

Clinical course in patient from onset of syndrome similar to thrombotic thrombocytopenic purpura to clinical resolution and reinstitution of chemotherapy.

$\mathbf{P}=$ Plasmapheresis. $\mathbf{P C}=$ Transfusion with packed red blood cells. Stippled areas indicate normal ranges. 
packed cell volume, haemoglobin concentration, white cell count, and platelet count remained normal. Haptoglobin concentration was greater than $1.0 \mathrm{~g} / 1(100 \mathrm{mg} / 100 \mathrm{ml}$ ) (normal 0.5-1.0 g/1;50-100 mg/ $100 \mathrm{ml}$ ). In December 1980, with no evidence of malignancy on clinical evaluation, she underwent abdominal re-exploration. No gross tumour was detected, and multiple full-thickness biopsy specimens of the stomach failed to show residual adenocarcinoma. Chemotherapy was stopped, and she remained in complete tumour remission and with no evidence of a recurrence of thrombotic thrombocytopenic purpura.

\section{Discussion}

The patient described in this case report developed a syndrome similar to thrombotic thrombocytopenic purpura without evidence of disseminated intravascular coagulation while in a complete response after chemotherapy with fluorouracil, doxorubicin, and mitomycin. The finding of immune complexes, whose concentration decreased in parallel with clinical improvement, suggests an immune mechanism. This was further supported by the finding that one of the antibodies in the circulating immune complexes showed a strong cross-reaction to tumour antigen. We hypothesise that a pre-existing state of antigen excess decreases as the tumour is reduced by chemotherapy, thus allowing for the formation of soluble antigenantibody complexes. Antigen-antibody complexes have been found in high titres in patients with malignancy 22-24 and can induce release of platelet substances in vitro that can potentially initiate intravascular coagulation. ${ }^{25-27}$ Such immune complexes could accumulate in the blood vessels, causing local vascular injury as well as initiating deposition of platelets and fibrin, leading to the clinical syndrome described. Certainly the presence of a platelet-aggregating immune complex in this case lends support to this theory. In addition, the finding of platelet glycoprotein as the antigen in one of the immune complexes identified in this patient indicates that there is an immune reaction to the platelets, due either to an antibody previously formed reacting with normal, intact platelets or to an antibody response to platelet injury.

Combination chemotherapy, and in particular mitomycin, has recently been implicated as the factor responsible in two patients with gastric carcinoma who developed this syndrome, ${ }^{5}$ but the evidence is only speculative. Although nephrotoxicity associated with mitomycin is said to occur in as many as $10 \%$ of patients, it appears to be dose related. ${ }^{28}$ Our patient received $10 \mathrm{mg}$ mitomycin $/ \mathrm{m}^{2}$ every eight weeks, giving a total dose of $40 \mathrm{mg} / \mathrm{m}^{2}$ at the time of onset of the syndrome, which is less than is usually reported for nephrotoxicity. ${ }^{29}$ The renal histology in our previous cases ${ }^{4}$ and those of Jones et $\mathrm{al}^{5}$ is not consistent with that described with mitomycin nephrotoxicity ${ }^{28}$ but conforms with the histopathology of thrombotic thrombocytopenic purpura. We have attempted to identify mitomycin as an antigen in the antigen-antibody complex but cannot find a line of identity. While we have observed this syndrome in patients with gastric cancer treated with a mitomycin-containing combination, we have not observed it in patients with adenocarcinoma of the lung treated with the same regimen. ${ }^{30}$

As treatment of gastric cancer improves and increasing numbers of patients achieve the striking response observed in the present case this syndrome, similar to thrombotic thrombocytopenic purpura, may become more common. Patients should be monitored carefully for haemolytic anaemia and renal impairment, and signs of pancytopenia should not be automatically ascribed to myelosuppressive treatment. Plasma samples should be obtained for determination of immune complex concentrations in patients who develop this syndrome, and empiric treatment with plasmapheresis and azathioprine should be started.

Requests for reprints should be addressed to: Professor Philip S Schein, Georgetown University Hospital, Room 2230, 3800 Reservoir Road NW, Washington, DC 20007, USA.

\section{References}

${ }^{1}$ Antman KH, Skarin AT, Mayer RJ, Hargreaves HK, Canellos GP Microangiopathic hemolytic anemia and cancer: a review. Medicine (Baltimore) 1979;58:377-84.

${ }^{2}$ Lohrman HP, Adam W, Heymer B, Kubanek B. Microangiopathic hemolytic anemia in metastatic carcinoma. Ann Intern Med 1973;79: 368-75.

${ }^{3}$ Brain MC, Azzopardi JG, Baker LRI, Pineo GF, Roberts PD, Dacie JV. Microangiopathic hemolytic anemia and mucin-forming adenocarcinoma. Br f Haematol 1970;18:183-93.

${ }^{4}$ Kressel BR, Ryan KP, Duong ATT, Berenberg J, Schein PS. Microangiopathic hemolytic anemia, thrombocytopenia and renal failure in patients treated for adenocarcinoma. Cancer 1981;48:1738-45.

${ }^{5}$ Jones BG, Newman GE, Fielding JW, Howell A, Brookes VS. Intravascular haemolysis and renal impairment after blood transfusion in two patients on long-term 5-fluorouracil and mitomycin-C. Lancet $1980 ; \mathrm{i}: 1275-7$.

6 Gulati SC, Sordillo P, Kempin S, et al. Microangiopathic hemolytic anemia observed after treatment of epidermoid carcinoma with mitomycin-C and 5-fluorouracil. Cancer 1980;45:2252-7.

${ }^{7}$ Levine S, Shearn MA. Thrombotic thrombocytopenic purpura and systemic lupus erythematosus. Arch Intern Med 1964;113:826-36.

${ }^{8}$ Dekker A, O'Brien ME, Cammarata RJ. The association of thrombotic thrombocytopenic purpura with systemic lupus erythematosis. $A m \mathcal{F}$ Med Sci $1974 ; 267: 243-9$.

9 Morrison J, McMillan R. Elevated platelet-associated IgG in thrombotic thrombocytopenic purpura. $\mathcal{f} A M A$ 1977;239:1944-5.

${ }^{10}$ Kelton JG, Neame PB, Walker J, Turple AG, Nicholson W, Hirsh J. Thrombotic thrombocytopenic purpura: mechanism for effectiveness of plasmapheresis. Clin Res 1979;27:299A.

11 Mant MJ, Cauchi MN, Medley G. Thrombotic thrombocytopenic purpura: report of a case with possible immune etiology. Blood 1972; 40:416-21.

12 Bukowski RM, King JW, Hewlett JS. Plasmapheresis in the treatment of thrombotic thrombocytopenic purpura. Blood 1977;50:413-7.

13 Ryan PFJ, Cooper IA, Firkin BG. Plasmapheresis in the treatment of thrombotic thrombocytopenic purpura : a report of five cases. Med $\mathcal{f}$ Aust $1979 ; 1: 69-72$.

14 Neame PB, Hirsh J. Circulating immune complexes in thrombotic thrombocytopenic purpura (TTP). Blood 1978;51:559.

15 Aster RH. TTP: new clues to the etiology of an enigmatic disease. $N$ Engl I Med 1977;297:1400-1.

${ }^{16}$ Sacher RA, Phillips TM, Shashaty GG, Jacobson RJ, Rath CE, Lewis MG. Demonstration of immune complexes in thrombotic thrombocytopenic purpura and effect of exchange transfusion. Scand $\mathcal{F}$ Haematol 1980; 24:373-80.

17 Macdonald JS, Schein PS, Woolley PV, et al. 5-Fluorouracil, doxorubicin, mitomycin-C (FAM) combination chemotherapy for advanced gastric cancer. Ann Intern Med 1980;93:533-6.

${ }^{18}$ Heusser C, Boesman M, Wordin JH, Isliker $\mathrm{H}$. Effect of chemical and enzymatic radioiodination on in vitro human Clq activities. $f$ Immunol $1973 ; 110: 820-8$.

19 Theofilopoulos AN, Wilson CB, Dixon FJ. The Raji cell radioimmune assay for detecting immune complexes in human sera. $\mathcal{F}$ Clin Invest 1976;57:169-82.

20 Phillips TM, Draper C. Circulating immune complexes in schistosomiasis due to Schistosoma mansoni. Br Med $\mathcal{f} 1975$;ii:476-7.

21 Phillips TM, Lewis MG. A system of immunofluorescence in the study of tumor cells. Revue d'Etudes Cliniques et Biologiques 1970;15:1016-20.

22 Theofilopoulos AN, Andrews BS, Urist MM, Morton DL, Dixon FJ. The nature of immune complexes in human cancer sera. $\mathcal{F}$ Immunol 1977;119:657-63.

${ }^{23}$ Yoshida R, Zawadzki ZA. Circulating immune complexes in patients with neoplastic disorders. Oncology 1980;37:152-6.

${ }^{24}$ Lewis MG, Loughridge LW, Phillips TM. Immunologic studies in nephrotic syndrome associated with extra-renal malignant disease. Lancet 1971 ;ii:134-5.

${ }^{25}$ Lee L. Antigen-antibody reaction in the pathogenesis of bilateral renal cortical necrosis. $\mathcal{F}$ Exp Med 1963;117:365-75.

${ }^{26}$ Henson PM. Role of complement and leukocytes in immunologic release of vasoactive amines from platelets. Fed Proc 1969;28:1721-8.

${ }^{27}$ Movat HZ, Mustard JF, Taichman NS, Uriuhara T. Platelet aggregation and release of ADP, serotonin and histamine associated with phagocytosis of antigen-antibody complexes. Proc Soc Exp Biol Med 1965;120:232-7.

${ }^{28}$ Lui K, Mittelman A, Sproul EE, Elias EG. Renal toxicity in man treated with mitomycin-C. Cancer $1971 ; 28: 1314-20$.

29 Ratanatharathorn V, Baker LH, Cadnapaphornchai P, Rosenberg BF, Vaitkevicius VK. Clinical and pathological study of mitomycin-C nephrotoxicity. In: Carter SK, Crooke ST, eds. Mitomycin-C: current status and new developments. New York: Academic Press, 1979:214-29.

30 Butler PT, Macdonald JS, Smith FP, Smith LF, Woolley PV, Schein PS. 5-Fluorouracil, adriamycin, and mitomycin-C (FAM) chemotherapy for adenocarcinoma of the lung. Cancer $1979 ; 43: 1183-8$.

(Accepted 24 February 1982) 